\title{
Health Care Needs of Iraqi Refugees Presenting to the Kurdish Red Crescent Clinics in the Al Hol Camp During 12 Months of on-going Conflict: A Cross-sectional Study. Short Title Complex Humanitarian Emergencies: Idp and Refugee Health Care Needs
}

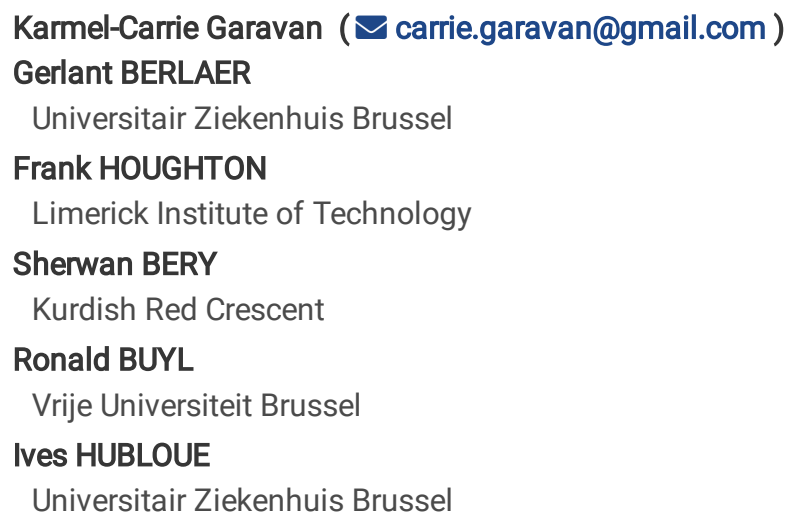

\section{Research Article}

Keywords: Syria, Iraqi refuges, Complex Humanitarian Emergency, healthcare, refugees, conflict, displacement, morbidity, mortality

Posted Date: February 16th, 2022

DOI: https://doi.org/10.21203/rs.3.rs-1343070/v1

License: (c) (i) This work is licensed under a Creative Commons Attribution 4.0 International License. Read Full License 


\section{Abstract}

\section{Background}

The Battle for Mosul began in October 2016 as the world's single largest military operation since the 2003 invasion of Iraq. In anticipation of massive displacement of Iraqi refugees, the Al-Hol camp was erected at the Iraqi-Syrian border meant to respond to the immediate needs of about 100,000 people. The Kurdish Red Crescent (KRC) in partnership with Un Ponte Per (UPP) operated two clinics in the camp, receiving over 200 patients daily.

This study aims to describe health services utilisation, complaints, diagnoses and treatment of Iraqi war refugees in the camp and make recommendations to improve humanitarian response for these vulnerable populations.

\section{Methods}

By means of a cross-sectional analysis of all patient data collected in two primary healthcare clinics and an emergency room in the camp between March 2017 and March 2018 are reviewed and analysed, regarding demographics, complaints at presentation, diagnoses and treatment.

\section{Results}

Of all 148,743 patient contacts, 93,341 were individual consultations with health services provision to registered Iraqi refugees in both clinics, and 55,402 were Emergency Room encounters.

Most frequent specific complaints (over 20\%) were of respiratory origin (including infections and asthma), watery diarrhoea (8\%) and urinary tract infections (7.6\%). Urinary tract infections, anaemia and vaginal discharge were common among the female population. Noncommunicable diseases like diabetes and arterial hypertension were frequent and consistent complaints throughout the year equally in male and female adults. Skin diseases included over 700 cases of leishmaniosis, mainly in the older population and in the first months. Mental health disorders remained under detected and $44 \%$ of diagnoses were categorised as unknown or "other". There were 302 live births, and the highest Crude Mortality Rate (0.21) was in week 33.

Emergency treatment included nebulisations, dressings, injections, suturing, splinting, and stabilization prior to referral to more advanced care outside the camp.

\section{Conclusions}

Many Iraqi refugees in Al-Hol sought treatment for illnesses associated with prolonged poor living conditions, combined with seasonal variations in hostile desert climate: respiratory tract infections mainly seen in children, gastrointestinal diseases, urinary tract infections, and gender specific complaints of vaginal discharge and anaemia.

\section{Background}

The world's largest single military operation since the 2003 invasion of Iraq began on October $16^{\text {th }}, 2016$, targeting the areas around Mosul in the Iraqi Nineveh Governorate controlled by the Islamic State of Iraq and the Levant (ISIL). This event led to displacement of over 400,000 people in the first two months and continued throughout 2016 and 2017 forcing people to flee across the border into the neighbouring AlHasakeh Governorate in North Eastern Syria (UNHCR, 2018).In anticipation of this influx of Iraqi refugees, the Al-Hol refugee camp was developed at the Iraqi-Syrian border as part of a preparedness plan to respond to the immediate needs of an estimated 100,000 refugees.

From October 2016, thousands of Iraqi refugees were received in Al-Hol, reaching 20,000 individuals by April 2017, and peaking to over 25,000 in October 2017. (Figure 1) By July 2018, the camp population had shrunk to 11,300 with many Iraqis returning home following the liberation of Mosul and surrounding cities (REACH, 2018). At the time of arrival of the Medical Coordinator in the camp in October 2017 there were almost 6,000 families in Al-Hol with an average of 6.2 persons per household (Suppl. Figure 3), located in about 4,000 shelters divided into six areas ("phases"). With an average of five persons per shelter (mostly tents), the average covered area per person was $3.5 \mathrm{~m}^{2}(\mathrm{REACH}$, 2018). The largest two phases sheltered Iraqi refugees (97\% of camp population) primarily from Nineveh governorate (REACH, 2017), whilst one was for Syrian IDPs (remaining 3\%) primarily from Deir-Ez-Zor, Al-Hasakeh and Ar-Raqqa governorates. Camp demographics indicated a young population with $57-61 \%$ under the age of 18 years during the 12 months of data collection (Table 1 Supplementary: Age groups of Iraqi refugees Al Hol Camp March 2017-March 2018). [UNHCR, personal communication]. 
Iraqis fleeing the Battle for Mosul during 2016 and 2017 sought primarily safe haven in Syria, more than in Jordan and Lebanon. However, Syria was already ravaged by war since March 2011 with conflict being the country's leading cause of death ever since (Guha-Sapir, Rodiriquez-Llanes, Hicks, Donneau, Coutts, Lillywhite, Foua, 2015), and suffering a severe public health crisis (Cousins, 2015) as Syria's National health care system and services were already under immense pressure.

Few countries in the world today remain untouched by those forced to flee their homeland in search of protection from persecution (Begley, Garavan, Condon, Kelly, Holland \& Staines, 1999). Displacement of populations can occur due to factors associated with natural or manmade disasters including conflict and war. Those displaced remaining within their home country are known as "internally displaced people" (IDPs), while people forced to flee to another country are "asylum-seekers". Once recognised by their new country, they are granted the official state of "refugee" (UNHCR, 2007). Asylum seekers and refugees leave their country because their choice is stark: flee, or stay and risk their and their family's life. Displaced people endure violations of human rights, repression, conflicts and brutal political persecution, all of which continue to contribute to the flight and mass migration of millions of people every year. The global numbers of people seeking refuge across borders has risen dramatically in the last decade. When the United Nations High Commission for Refugees (UNHCR) was founded in 1951, there were an estimated 1.5 million refugees worldwide. In 2018, an unprecedented 68.5 million people have been forced from home, of whom nearly 25.4 million refugees, over half under the age of 18 . An estimated 10 million stateless people have been denied a nationality and access to basic rights such as education, healthcare, employment and freedom of movement. In the world today, nearly one person is forcibly displaced every two seconds as a result of conflict or persecution (UNHCR, 2018).

The need to be creative in ensuring that refugees receive adequate health coverage in conflict settings has evolved over time: UNHCR now partners with national and international non-governmental organisations (NGOs) to provide outpatient health services and a referral system to access host communities, in-patient services and specialist consultancy services. In the 1980's, the UNICEF/WHO Alma Ata Declaration influenced international public health stating that refugee health programs should be based on the Primary Health Care model (Dick, Simmonds \& Vaughan, 1983). In recent decades the burden of caring for refugees has fallen on international relief organizations, and the World Health Organization (WHO) and United Nations (UN) have partnered with several NGOs to promote healthcare for IDPs and refugees.

A body of evidence on the considerable effect of war on public health has accumulated over the past 25 years (Borton, 1996; Levy \& Sidel, 1997). In a series of articles on public health and humanitarian interventions on developing the evidence base on conflict and health, it has been argued that there are practical, ethical, logistical, and security issues in the undertaking of research during conflict or political violence. While it is feasible to collect data on health services and health problems, understanding how best to upgrade health services for the host population alongside those available to refugees, and how to most humanely and efficiently provide good quality services and identify key determinants for inter-agency and inter-sectoral cooperation and coordination is key (Banatula and Zuri, 2000).

Of all disasters, the effects of armed conflicts on public health are probably of the greatest magnitude because of the initiation of mass movement and displacement of populations. Under such arduous state, people - in particular the youngest and oldest exposed to challenging environments - have a propensity to danger, injuries and exacerbation of underlying or chronic medical conditions. Although it is a common belief that high death rates are due to direct injury like gunshots, mortars, or explosions, the truth is that an overwhelming majority of morbidity and mortality caused by armed conflict is indirect and relates mainly to public health issues (Murray, King, Lopez, Tomijima, Krug (2002).

The impact of civil wars hypothesis has been tested and found to have substantial long-term effects, even after controlling for several other factors. Using data from 1991-1997, it was estimated that the additional burden of death and disability from the indirect and lingering effects of civil war was approximately equal to that incurred directly and immediately from all wars, and that the impact worked its way through specific diseases and conditions, disproportionately affecting women and children (Ghobarah, Huth, Russett (2003). The disease burden is not directly combat-related but is multifactorial and due to malnutrition, communicable diseases and exacerbation of chronic conditions. The main public health risk factors that emerge in crises are detailed by Checci, Warsame, Treacy-Wang, Polonsky, van Ommeren and Prudhon, (2017) who stress that while humanitarian public health services (water, sanitation and hygiene, nutrition and health care) seek to minimise excess health impact by reducing exposure to the risk factors, they must be available and have both high coverage and high quality.

Several of these contributing factors have been well documented: as a result of a disaster or its consequences people may suffer from specific injuries, infections (communicable diseases) destabilisation of chronic (non-communicable diseases), mental health disorders and other problems such as premature births (van Berlaer, Elsafti, Al Safadi, Souhil Saeed, Buyl, Debacker, 2017).

Forced displacement, particularly into overcrowded settlements with poor living conditions results in greater infectious disease transmission (Connolly, Gayer, Ryan, Salama, Spiegel Heymann, 2004), including upper and lower respiratory tract infections, acute watery diarrhoea, skin diseases, and fever of unknown origin in the Cox Bazzar Refugee camp in Bangladesh (MSF, 2019).

Page $3 / 17$ 
Communicable diseases, alone or in combination with malnutrition, account for most deaths in complex emergencies (Connolly, Gayer, Ryan, Salama, Spiegel, Heymann (2004). Controlling specific communicable diseases in camp settings is a challenge. The WHO supported NGO Mentor Initiative [MENTOR, 2019] has been coordinating the response to outbreaks within Syria. The number of cases of cutaneous leishmaniasis, endemic in Syria since the 18th century and formerly considered an urban problem centred around Aleppo and Idlib, have dramatically increased since the conflict, and spread within Syria and into neighbouring Iraq, Lebanon, and Jordan (Burki, 2017, Salam, AlShaqha, Azzi (2014): Hayani, Dandashli, Weisshaar (2015): Alasaad (2013). 41\% of the consultations of Syrian refugees seeking primary medical care in neighbouring countries Jordan, Turkey and Lebanon, are for respiratory tract infections (UNHCR, 2015), reflecting the impaired living conditions both inside and outside refugee camps (Sahloul, Monla-Hassan, Sankari, Kherallah, Atassi, Badr, Abbara Sparrow, 2015).

The breakdown of healthcare systems is a reverberation of internal conflict, leading to shortage of routine daily treatment and necessary health services for the chronically ill. Non-communicable diseases (NCDs) are the leading cause of mortality worldwide with an estimated 41 million deaths in 2016 , accounting for $71 \%$ of 57 million deaths annually. (WHO, 2018). In Iraq, chronic disease accounts for $43 \%$ of all deaths, $21 \%$ of which are cardiovascular (WHO, 2018).

There is limited data reported on the mental health issues of Iraqi refugees (Mateen, Carone, Al-Saedy, Nyce, Ghosn, Mutuerandu, Black, 2010) (Yanni, Naoum, Odeh, Han, Coleman, Burke (2013).

Humanitarian intervention is aimed at saving lives, alleviating suffering and maintaining human dignity of all. The Core SHPERE and minimum standards cover approaches to programming four sets of life-saving activities: water supply, sanitation and hygiene promotion; food security and nutrition; shelter, settlement and non-food items; and health action (SPHERE Project, 2011). Access to primary health care and referral hospital services for treatment of severe cases is one of the top ten interventions to reduce mortality in the acute phase of an emergency and beyond.

Healthcare workers delivering medical care to the affected people in humanitarian emergencies thus require specific knowledge about the diagnosis and treatment of the most common health conditions in refugees (Wisner \& Adams, 2002) and should be capable of adapting to complex circumstances. Well trained international emergency personnel need to switch from their daily routine of attempting to save every patient, to a disaster mode of "doing the best for most", taking into account the number of patients and the availability of time, human and medical resources (Merin, Ash, Levy, Schwaber, Kreiss, 2010).

In order to assemble a body of evidence needed to improve future humanitarian interventions, it is of the utmost importance that well organised health systems support on-going prospective collection of epidemiological data during disasters (Checci and Roberts 2005). Next to the ethical duty to publish scientific reports timely, healthcare workers need to monitor, record, and report patient's complaints and diagnoses as a surveillance in real time, in order to be alerted immediately when notifiable or priority diseases emerge in the population.

Despite the large numbers of Iraqi refugees recognised by UNHCR, there are few published studies on their health state, mostly because host country surveillance systems do not disaggregate by nationality (Mowafi, Spiegel, 2008). Some publications have documented the health of Iraqi refugees living in camps in Jordan (Mateen, Carone, Al-Saedy, Nyce, Ghosn, Mutuerandu, Black, 2010) or resettled in European countries (van Berlaer, 2016) and have concluded that next to infectious diseases, they suffer predominantly from long neglected or untreated chronic conditions, emphasising the need for early prevention and control, and targeted health services and education.

In the light of this paucity of data on the health state of Iraqi refugees living in camps within conflict zones in Syria, to our knowledge this study is the first to report on the prevalence and healthcare seeking conditions for Iraqi refugees displaced into North Eastern Syria during the Battle for Mosul.

\section{Objectives}

The aim of this study is to describe the presenting complaints, diagnoses and treatment of Iraqi war refugees in a UNHCR camp located in North Eastern Syria, and to determine the range and burden of health services utilisation in order to make recommendations on how best to improve the humanitarian response regarding the composition of the health services provided and medial team resources required to respond to these vulnerable populations.

\section{Methods} Study design 
A retrospective cross-sectional observational sample analysis was performed on medical health card records, obtained and collected by Kurdish Red Crescent (KRC) and the Italian NGO Un Ponte Per (UPP) during twelve months between March 2017 and March 2018 , in the AlHol refugee camp in North Eastern Syria. The study protocol was approved by the Ethical Committee of the Universitair Ziekenhuis Brussel, Belgium. A data sharing and research collaboration agreement was signed between UPP and the researchers. KRC obtained permits to perform medical work in Syria, and approval to collect medical data as necessary for scientific studies, conducted in compliance with the relevant international regulations and laws.

\section{Setting}

Patients were recruited within two clinics, opened and located respectively in June (at the main gate of phase 1) and July 2017 (inside phase 4), and jointly operated by KRC in partnership with UPP. Both international partners were invited by UNHCR and given a mandate in the light of the UNHCR vision [UNHCR, 2007] to provide health services to refugees in the Al-Hol camp on the Iraqi-Syrian border.

Both clinics were run $24 / 7$ by a staff of physicians (3 general, 2 paediatricians, 1 obstetrician/gynaecologist), midwifes and specialist nurses, and received up to 200 patients per day in a system of quota of 50 consultations per day per specialty, introduced in June 2017 (week 13) according to SPHERE Guidelines (SPHERE Project, 2011). This system had an impact on the numbers.

Most patients presented early morning forming queues outside the main door, as there was only one registration point. Usually by noon the congestion had eased. All patients not possessing health cards were required to register at the reception prior to seeing the doctor or nurse.

The KRC Health Promotion Team went through the crowd, checking if the patient possessed a health card (directing them to a separate cabin to issue one if not), ascertained and directed the patient to a waiting area ("grand arena") in front of the cabin of the most appropriate specialist.

The largest clinic consisted of four cabins in a main arena: one served as a pharmacy, one as a laboratory and phlebotomy station, and two as medical consultation cabins. The lab and pharmacy operated from 08:00 to 18:00 hours. An emergency drug supply was held in the emergency room at all times.

This second clinic located in phase 4 was smaller, with cabins arranged in a square around a central waiting area located after the triage station, and with daily attendance numbers increasing gradually over the data collection period (July 2017- March 2018). Registration was done inside the main area. Per shift there was a general physician on duty, a paediatrician, gynaecologist with a midwife, lab and pharmacy technicians. Female patients were not examined by the male gynaecologist but by the midwife who then consulted with the gynaecologist for treatment to be prescribed as needed. This clinic operated from 08.00 to 18.00 and all patients requiring more advanced care and treatment were then seen in the clinic in Phase 1.

Health Services were provided for free to the Iraqi refugee population by KRC, funded by UPP, and mandated by the UNHCR.

\section{Participants}

In a simple random sampling, all Iraqi refugees of any age or gender, registering as patients for medical consultation in one of both clinics were eligible to be included. In accordance with the Ethical Committee of the Universitair Ziekenhuis Brussel, Belgium, informed consent from the patients was obtained orally before the medical exam. There has been no other filtering or restriction in selection of samples for this study.

Patients were post-hoc categorised into two age groups: under five and over 5 years of age, including adults.

\section{Variables, data collection and data entry}

Data were collected by KRC trained project data entry workers and entered in a specifically developed software programme registration system, based on KRC's Family Health Cards [Suppl. Information Figure 2]. The paper form of these cards was distributed across the camp phases on a recurring basis, as a preparation for the actual medical visit.

Registered information during each visit the patient's included the patient's age category (under or over five years of age), gender, medical and other chief complaints at the time of presentation, the type of consultation received, the primary diagnosis as made by a physician, and the provided treatment. 
Patients' complaints at presentation were recorded according to a template list of 33 possible predefined categories, including the additional categories of "other" and "unknown". Over the 12 months of data collection, some of the complaints and diagnosis categories were amalgamated, while others were removed. This kind of template has been used in previous humanitarian operations by a number of governmental and non-governmental organisations, and was adapted from case descriptions in the WHO "Communicable disease control in emergencies" field manual and the Sphere Project Handbook [SPHERE, 2011]. Diagnoses were categorised according to the International Classification of Diseases (ICD-10) [Version, 2016]. A new system collecting more detailed information was introduced at the end of this study, in March 2018.

Data were collected and collated weekly, entered into an excel file, aggregated and used to compile weekly reports on project activities for both the health services provider and the donor.

Detailed data were only accessible to KRC data entry personnel and senior KRC and UPP management, and were anonymised for this study. Data accuracy was ensured with the use of drop down menus, routine checks, weekly report generation and regular communication between the data collecting staff, the project management, and the health service provider management.

\section{Statistical analysis}

Patient records with missing or unreadable data were excluded. Descriptive statistics for discrete outcome variables were presented as frequencies and proportions ( $\mathrm{n}$ \% \%), and for quantitative variables (age, number of patients) as median, range, and interquartile range (IQR). The analyses were broken down for age ( $<5$ and $\geq 5$ years old) and clinic ( 2 phases and Emergency Room).

Basic descriptive statistics were used to characterise outcomes of interest in the study population. Disease burden was assessed using both generic (such as mental illness, skin diseases, and respiratory tract infection) and specific pre-defined categories (such as watery diarrhoea, leishmaniosis, and hepatitis).

\section{Results}

\section{Participants and demographics}

Of all 148,743 patient contacts during the 12 months of data collection, 93,341 were individual consultations with health services provision to registered Iraqi refugees in the two clinics (phase 1 and phase 4) of the Al-Hol camp, and 55,402 were Emergency Room encounters.

The monthly number of consultations increased gradually over the year. When dividing the number of consultations by the number of registered Iraqi refugees in the camp during each month (data supplied by UNHCR), a peak of $66 \%$ of the total camp population seeking health care services was reached by February 2018 (Figure 1).

Paediatric consultations accounted for $37 \%$, internal medicine consultations for $35 \%$, whereas the additional categories of "others" and "unknown" accounted for $44 \%$ of all consultations $(n=44,613)$ as indicated in Supplemental Figure 4.

A number of other services and their utilization rates were recorded and monitored during the data collection period of March 2017-March 2018. A 24/7 operational emergency room (ER) was added to the main primary health care clinics in week 13 (June 2017). This ER received all emergency cases via the triage nurse at the main reception. The number of patients seen in the ER was 55,402 over the data collection period of 53 weeks or 12 months: 32,164 during day shifts, and 23,238 during night shifts (Figure 2). Emergency treatment included nebulisations, dressings, injections, suturing, splinting, and stabilization prior to referral to more advanced care outside the camp.

\section{Outcome data}

Table 1: Number and percentage of encountered diagnoses in ICD categories 


\begin{tabular}{|c|c|c|c|c|c|c|c|}
\hline Category & $\mathrm{n}$ & $\%$ & diagnosis & $\begin{array}{l}\mathrm{n}<5 \text { years } \\
\text { old }\end{array}$ & $\begin{array}{l}n \geq 5 \text { years } \\
\text { old }\end{array}$ & $\begin{array}{l}\mathrm{n} \text { (all } \\
\text { patients) }\end{array}$ & $\%$ \\
\hline \multirow[t]{3}{*}{ Respiratory } & \multirow[t]{3}{*}{19798} & \multirow[t]{3}{*}{21,2} & Respiratory tract infection & 9917 & 8606 & 18523 & 19,8 \\
\hline & & & Bronchial asthma & 104 & 160 & 264 & 0,3 \\
\hline & & & Acute respiratory infection & 475 & 536 & 1011 & 1,1 \\
\hline \multirow[t]{5}{*}{ Intestinal } & \multirow[t]{5}{*}{9862} & \multirow[t]{5}{*}{10,6} & Watery diarrhoea & 4047 & 3433 & 7480 & 8,0 \\
\hline & & & Bloody diarrhoea & 30 & 62 & 92 & 0,1 \\
\hline & & & Malnutrition & 265 & 601 & 866 & 0,9 \\
\hline & & & Worms & 45 & 498 & 543 & 0,6 \\
\hline & & & Lower abdominal pain & 1 & 880 & 881 & 0,9 \\
\hline \multirow[t]{2}{*}{ Genitourinary } & \multirow[t]{2}{*}{8414} & \multirow[t]{2}{*}{9,0} & Urinary tract infection & 1523 & 5597 & 7120 & 7,6 \\
\hline & & & Vaginal discharge & 96 & 1198 & 1294 & 1,4 \\
\hline \multirow[t]{3}{*}{ Circulatory } & \multirow[t]{3}{*}{6528} & \multirow[t]{3}{*}{7,0} & Ischemic heart disease & 116 & 1394 & 1510 & 1,6 \\
\hline & & & Arterial hypertension & 132 & 3482 & 3614 & 3,9 \\
\hline & & & Anaemia & 302 & 1102 & 1404 & 1,5 \\
\hline \multirow[t]{2}{*}{ Skin } & \multirow[t]{2}{*}{2855} & \multirow[t]{2}{*}{3,1} & Skin disease & 675 & 1439 & 2114 & 2,3 \\
\hline & & & Leishmaniosis & 125 & 616 & 741 & 0,8 \\
\hline NCD & 2396 & 2,6 & Noncommunicable diseases & 512 & 1884 & 2396 & 2,6 \\
\hline Mental & 671 & 0,7 & Mental disorder & 151 & 520 & 671 & 0,7 \\
\hline Eye & 614 & 0,7 & Eye disease & 241 & 373 & 614 & 0,7 \\
\hline \multirow{6}{*}{$\begin{array}{l}\text { Systemic } \\
\text { infections }\end{array}$} & \multirow[t]{6}{*}{590} & \multirow[t]{6}{*}{0,6} & Hepatitis - suspected & 3 & 0 & 3 & 0,0 \\
\hline & & & Hepatitis - confirmed & 0 & 0 & 0 & 0,0 \\
\hline & & & Fever of unknown origin & 296 & 272 & 568 & 0,6 \\
\hline & & & Malaria - suspected/confirmed & 1 & 0 & 1 & 0,0 \\
\hline & & & Acute jaundice syndrome & 0 & 8 & 8 & 0,0 \\
\hline & & & $\begin{array}{l}\text { Acute haemorrhagic fever } \\
\text { syndrome }\end{array}$ & 4 & 6 & 10 & 0,0 \\
\hline \multirow[t]{2}{*}{ Other } & \multirow[t]{2}{*}{41613} & \multirow[t]{2}{*}{44,6} & Other diagnoses & 6895 & 27538 & 34433 & 36,9 \\
\hline & & & Unknown & 656 & 6524 & 7180 & 7,7 \\
\hline Total & 93341 & 100,0 & & 26612 & 66729 & 93341 & 100,0 \\
\hline
\end{tabular}

Most frequent specific chief complaints (over 20\%) upon presentation were of respiratory origin (including infections and asthma), watery diarrhoea ( $8 \%$ ) and urinary tract infections (7.6\%). The most frequent specific chief diagnoses were respiratory tract infections ( $n=18,523$ or $19.8 \%$ of all consultations), followed by watery diarrhoea $(n=7480 ; 8 \%)$, and urinary tract infections $(n=7120$ or $7.6 \%)$. None of the other infections reached $5 \%$ of all diagnoses (Figure 3 ).

When clustering diagnoses following an adapted system-based ICD-10 categorisation, respiratory diseases accounted for $21.2 \%$ of all consultations, followed by intestinal (10.6\%), genitourinary (9\%), and circulatory disorders (7\%) as indicated in Figure 4 .

Urinary tract infections, anaemia and vaginal discharge were common among the female population. Non-communicable diseases like diabetes and arterial hypertension were frequent complaints presenting consistently throughout the year equally in male and female adults. Skin diseases included over 700 cases of leishmaniosis, mainly in the older population and in the first months. Mental health disorders remained under detected and $44 \%$ of diagnoses were categorised as unknown or "other". There were 302 live births, and the highest Crude Mortality Rate (0.21) was in week 33. 


\section{Communicable diseases}

As time progressed, there was a vast increase in the number of cases of acute respiratory tract infections, with a peak in the winter months of January and February 2018. A less spectacular but steady increase was seen in acute watery diarrhoea cases as well (mostly and consistently to be contributed to the patients aged under five), and urinary tract infections, both of which followed the trend of increasing steadily over the study period and the peak of respiratory infections in February and March 2018. There was however also a tendency of temporary increase in presentations of urinary tract infections during the summer months (Figure 5).

The most common causes for all laboratory confirmed diarrhoea were typhoid (positive Widal test, $\mathrm{n}=910$ ) followed by brucellosis (positive Wright test, $\mathrm{n}=860$ ).

Regarding UTIs there was a big difference between the age groups: in the under-five, boys $(n=694)$ and girls $(n=659)$ were equally affected, whereas females over 5 years old $(n=3006)$ were diagnosed far more often than males $(n=1375)$ of the same age group. The number of cases of vaginal discharge in females indicated an upward trend as their length of stay in the camp increased, with an increase in cases in February 2018 similar to other infections.

Skin infections and diseases were diagnosed in more than $3 \%$ of all consultations, and did not present a clear trend of increase over time. During the first 4 months of data collection, more skin diseases were diagnosed in children than in adults, but this trend changed over time. Most cases of Leishmaniosis ( $n>700$ ) were detected in the first months of the clinic opening, and occurred more frequently amongst the older (over-five) population.

\section{Non-communicable diseases}

Patients consulting for non-communicable diseases and concomitant prescriptions were predominantly and consistently female. While the number of consultations for arterial hypertension $(n=3,129)$ and diabetes mellitus $(n=2,396)$ remained consistent throughout the data collection period in both male and female adults, cases of anaemia were found up to three times more frequent amongst the female camp population, with a peak in detection rates in the beginning of 2018 (Figure 6). This rise in numbers is attributable to an increase of newly arrived camp residents seeking health services at that time (Figure 1).

\section{Mental health}

Although both clinics did not provide specific or specialised mental health services, patients presenting with existing mental health conditions either received assistance on the spot or were referred to more specialised facilities. The number of people presenting with mental health disorders remained low ( $n=671$ or $0.7 \%$ ) in comparison to other health problems (Figure 7), except at the end of 2017 and the beginning of 2018 .

\section{Birth and crude mortality rates}

In the clinic's delivery suite staffed $24 / 7$ by skilled midwifes, there were 302 live births during the data collection period, with a peak of 53 live births in November 2017 and a few months when no births were registered in the camp (Figure 8). Pregnant women requiring C-Sections were referred and transported by ambulance to Al-Hasaka governmental hospital.

Crude mortality rates were measured weekly within the camp and remained low throughout the data collection period: the highest was 0.21 in week 33 with 4 deaths registered (the reference indicator should be $<0.6$ ). However, they did not include those referred to other specialist services outside the camp of whom some may have died.

\section{Referrals to specialist services outside of the Al-Hol camp}

A referral system with a designated $24 / 7$ ambulance service was set up to refer and transport those needing advanced care or services that were not available within the camp (Figure 9). These included surgery, cardiac services, paediatric care, dermatology, ophthalmology, urology, dialysis, C-sections, and others. Obtaining permission and completing the necessary documentation for security reasons resulted often in long delays in referral time.

\section{Discussion}


The health care needs of people affected by conflict, with particular reference to Iraqi refugees, have been documented before (Spiegel, Checchi Colomba Paik, 2010). Data collected at the KRC clinics in Al-Hol camp provides a snapshot of the trends in the most common causes for visits. Respiratory tract infections were the most common illness (morbidity) seen in both clinics mainly in children, followed by gastrointestinal diseases and urinary tract infections, most likely reflective of the harsh living conditions within the camp coupled with the hostile climatic desert climate, too cold in the Winter and too hot in the Summer.

A systematic review to generate evidence on the burden of Acute Respiratory Infections (ARI) in crises and inform prioritisation of relief interventions, suggested very high excess morbidity and mortality (20-35\% proportional mortality) and case-fatality (up to 30-35\%) (Bellos, Mulholland, O Brien, Qazi, Gayer, Checchi 2010), figures echoed in other studies (Sahloul, Monla-Hassan, Sankari, Kherallah, Atassi, Badr, Abbara Sparrow, 2015). Amongst Iraqi refugees living in Jordanian camps, respiratory disease was the most common reason (11\%) for seeking acute care (Mateen, Carone, Al-Saedy, Nyce, Ghosn, Mutuerandu, Black, 2010).

The most common causes for all laboratory confirmed diarrhoea was typhoid (Widal test) followed by brucellosis (Wright test). In a recent report from MSF on Cox Bazzar Refugee camp in Bangladesh, it was reported that poor living conditions were the reason for the majority of diseases treated such as acute watery diarrhoea, upper and lower respiratory tract infections; skin diseases; and fevers of unknown origin, which can all be difficult to diagnose when laboratory services are not widely available (MSF, 2019).

Noncommunicable diseases like diabetes and hypertension were common reasons for encounter. This burden amongst the Iraqi population has been documented before (Mateen, Carone, Al-Saedy, Nyce, Ghosn, Mutuerandu, Black, 2010). Chronic diseases comorbidities accounted for a large burden of disease in the Iraqi population, one study reporting that $35 \%$ of Iraqi refugees screened for resettlement in the United States of America had at least one of three chronic medical conditions; hypertension, diabetes mellitus, or obesity (Yanni, Naoum, Odeh, Han, Coleman, Burke (2012).

Skin diseases were more frequent in children than in adults, again linked to poor access to clean water and the difficult living conditions with the environmental challenges of searing heat in the summer and cold winters with the use of kerosene heaters, all contributed to the numbers. Next to cases of scabies treated accordingly, leishmaniasis has been a public health concern, endemic in many areas within Syria and in some areas the most prevalent communicable disease. Cutaneous leishmaniasis is often associated with malnutrition, population displacement, poor housing and weakened immune systems. It can be mistaken for other diseases or malnutrition. Leishmaniasis in Syria has been monitored by MENTOR international (www.mentorinitative.org ), a-non-for-profit organisation, who reported a 40-fold increase in incidence of cases, with L. tropica as the predominant species causing nearly $80 \%$ of cutaneous lesions (Rehman, Walochnik, Mischlinger, Alassil, Allan Ramharter, 2018). A swift response by the MENTOR initiative to the influx of the Iraqis to the Al Hol camp in $2016-2017$ resulted in rapid identification and treatment of cases $(n=700)$ and a decrease in cases detected over time. The number of cases in Syrian IDPs is far higher than those detected in the camp of Al Hol amongst the Iraqi population. A survey amongst villages in Idlib found that the cases of visceral leishmaniasis were high (Rehman, Walochnik, Mischlinger, Alassil, Allan, Ramharter 2018) inferring hypothetically that the death toll from VS could be the second highest after mortality from the war itself (Burki, 2017). Control requires indoor residual spraying (IRS) of camp shelters and urban buildings, waste management and education and communication.

Humanitarian aid has relieved a significant burden of displaced people's basic needs, however mental and women's health needs remain largely unmet (Kim, Torbay, Lawry 2007). Women carry a significant burden of being displaced presenting with gender specific complaints such as anaemia and vaginal discharge. The results indicated an increasing number of cases of vaginal discharge over time, and seems again correlated with the amount of time spent in the camp. Access to private bathing or washing areas, and the environmental challenges of the cold winters and searing hot summers with no air conditioning or areas to seek refuge from the intense heat, most probably contributed to the number of cases.

Mental health has long been signalled as a core public health issue in complex emergencies (Burkel, 1999). Determining the prevalence of mental health issues among displaced populations within insecure environments has made some progress (Mollica, Lopes, Cardoza, Osofsky, Raphael, Ageer, Salama (2004). Neuropsychiatric disorders amongst refugee populations has been documented amongst Syrian and Iraqi refugees in Jordan (McKenzie, Spiegel, Khalifa, Mateen (2015) and is considered an important burden of health. The number of cases of mental health issues documented in this study was low in comparison to other health issues, most probably because the clinics did not provide the appropriate services.

\section{Limitations and strengths}

This study has all the inherent limitations of a cross sectional study. While it is a population based survey used to assess the prevalence of diseases in the clinics in the camp, it is a 1-time measurement of exposure and outcome, and it does not derive causal relationships. The 
study offers a point prevalence during 12 months of data collection, but does not measure a difference in health status before the conflict. Other limitations to this study are that the data is aggregate data not individual data and it is not age specific. There is an absence of indepth mental health data, and it is impossible to link any increase in the burden of disease with the challenging living conditions and displacement due to conflict. The strengths of the study are the considerable number of patient contact inclusions. This cross sectional study of health care records provides information on the presenting complaints of a refugee population displaced because of conflict within their own country (Iraq) and seeking refuge in a country in conflict (Syria), thus considered a complex humanitarian emergency.

\section{Conclusion}

Analysis of the data from Al Hol camp on the disease burden of the Iraqi refugees in NE Syria provides multiple learnings for humanitarian actors, the most important being that a long-term approach to health care provision must be the main focus. Non-communicable diseases constituted the burden of disease with ARI generating the greatest case load. Iraqi refugees accessed the health services within the camp but faced significant barriers to accessing specific specialist services outside the camp, which indicates a need for field hospitals and specialist services within the camp itself. Doctors, nurses, paramedics and international non-governmental organisations struggled to provide adequate health care and manage the consequences of those fleeing conflict, working under substandard conditions, without any field hospital or access to telehealth communication.

Improved collaboration between individuals in the field like UPP and KRC, and clinical researchers in academic environments can help promote an appropriate blend of operational expertise with the critical interpretation and dissemination of data. As far back as 1995 , a Lancet editorial argued that "academics may well be the best people to survey and audit the efforts of humanitarian agencies to mediate their interactions and help them achieve their common purpose" (Lancet, 1995)

\section{Recommendations}

Emergency medical teams providing healthcare in camps hosting war refugees should prepare properly in order to correctly fulfil their assignment. This means they have to compose their team of medical personnel in consideration of the large proportion of patients with acute respiratory, intestinal and genitourinary infections, mainly among respectively infants and children, and women. This means they have to include the required specialists amongst their team members, and provide the appropriate drugs and materials for treatment.

Humanitarian agencies need to include prevention and control of these types of infections spreading rapidly in crowded shelters and provide public health measures such as better housing and appropriate sanitary conditions.

Real time and detailed data collection should be improved, as timely early warnings about possible outbreaks or infectious disease spread, proper case management and vaccine strategies would help to reduce disease burden in these vulnerable populations.

\section{Abbreviations}

$\mathrm{Cl}$

$\mathrm{FH}$

EMT

IBM SPSS

ICD-10

IEHK

IQR

NCD

OR

WHO
Confidence Interval

Field Hospital

Emergency Medical Team

International Business Machines Corporation, Statistical Package for Social Science

International Classification of Diseases version 10

Interagency Emergency Health Kit

Interquartile range

Non-communicable diseases

odds ratio

World Health Organisation

\section{Declarations}




\section{Ethics approval and consent to participate:}

The study was approved by the Ethical Committee of the Free University of Brussels, Belgium. A data sharing agreement and research collaboration form was signed between Un Ponte Per (UPP) and the Research Group on Emergency and Disaster Medicine, VUB, Belgium, (Regedim).

\section{Consent for publication: not applicable}

\section{Availability of data and material:}

The datasets used and analysed during the current study are available from the corresponding author on reasonable request.

\section{Competing interests:}

The authors declare that they have no competing interests.

\section{Funding:}

There was no funding for this study.

\section{Authors' contributions:}

Protocol: KCG, GvB

Data Collection: KCG, UPP, KRC

Data analysis: KCG, RB

Manuscript: KCG, GvB, FH, SS, IH

Revisions: KCG, GvB, FH, UPP, KRC, SS, IH

All authors revised and approved the manuscript.

KCG: Karmel Carrie GARAVAN, GvB: Gerlant VAN BERLAER, FH: Frank HOUGHTON, SB: Sherwan BERY, RB: Ronald BUYL, IH: Ives HUBLOUE

\section{Acknowledgements:}

UPP, KRC, all health care workers in Al Hol

\section{Authors' information:}

carrie.garavan@gmail.com

gerlant.vanberlaer@uzbrussel.be

frank.houghton@lit.ie

sherwan.bery@hskurd.org

ronald.buyl@vub.be

ives.hubloue@uzbrussel.be

\section{References}

1. Alasaad S (2013). War diseases revealed by the social media: massive leishmaniasis outbreak in the Syrian Spring. Parasit Vectors.2013;6:94. [Available Online]. https://parasitesandvectors.biomedcentral.com/articles/10.1186/1756-3305-694_https://doi.org/10.1186/1756-3305-6-94_[Accessed February 2019].

2. Begley, M, Garavan, C, Condon, M, Kelly, I, Holland, K, Staines, A (1999) Asylum in Ireland - A Public Health Perspective. Project Report. Department of Public Health Medicine and Epidemiology, University College Dublin, and the Congregation of the Holy Ghost, Dublin. 
[Available online] http://doras.dcu.ie/14973. [Accessed November 2018].

3. Bellos A, Mulholland K, O'Brien KL, Qazi SA, Gayer M, Checchi F (2010). The burden of acute respiratory infections in crisis-affected populations: a systematic review. Conflict and Health. Feb 11;4:3. doi: 10.1186/1752-1505-4-3 [Available online] https://www.ncbi.nlm.nih.gov/pmc/articles/PMC2829474/ [Accessed November 2018].

4. Banatvala, N., \& Zwi, A. B. (2000). Conflict and health. Public health and humanitarian interventions: developing the evidence base. BMJ (Clinical research ed), 321(7253), 101-5. [Available online] https://www.ncbi.nlm.nih.gov/pmc/articles/PMC1127723/ [Accessed November 2018].

5. Borton, J (1996). Joint Evaluation of Emergency Assistance to Rwanda. The international response to conflict and genocide: lessons from the Rwanda experience Study 3: Humanitarian Aid and efforts. Odense: Steering Committee of the Joint Evaluation of Emergency Assistance to Rwanda. [Available online]. (https://www.files.ethz.ch/isn/121184/networkpaper016.pdf [Accessed November 2018].

6. Burki, T (2017). Leishmaniasis unleashed in Syria. Lancet, Infectious Diseases News desk Volume 17; Issue 2; P144-145. [Available online] https://www.thelancet.com/journals/laninf/article/PIIS1473-3099(17)30016-6/fulltext. doi: https://doi.org/10.1016/S14733099(17)30016-6. [Accessed November 2018].

7. Burkle, FM (1999). Lessons learnt and future expectations of complex emergencies. BMJ: 319:422 [Available Online] https://www.bmj.com/content/319/7207/422.short_[Accessed May_2019]_https://doi.org/10.1136/bmj.319.7207.422.

8. Checci, F., Roberts, L (2005). Interpreting and using mortality data in humanitarian emergencies A primer for non-epidemiologists. [Available online] https://odihpn.org/wp-content/uploads/2005/09/networkpaper052.pdf [Accessed November 2018].

9. Checci, F., Warsame, A., Treacy-Wong, V., Polonsky, J., van Ommeren, M., Prudhon, C (2017). Public Health information in crisis-affected populations: a review of methods and their use for advocacy and action. [Available online] https://www.thelancet.com/journals/lancet/article/PIIS0140-6736(17)30702-X/fulltext. [Accessed November 2018]. DOI:https://doi.org/10.106/so140-6736(17)30702-X.

10. Connolly, MA, Gayer, M., Ryan MJ., Salama, P., Spiegel, P., Heymann, D (2004). Communicable diseases in complex emergencies: impact and challenges. [Available online] Lancet: 364: 1974-83.

11. https://www.ncbi.nlm.nih.gov/pubmed/15567014. DOI:1016/S0140-6736(04)17481-3. [Accessed November 2018].

12. Cousins, S (2015) Syrian Crisis: health experts say more can be done. [Available online] Lancet 385: Issue 9972 931-934. Doi: https://doi.org/10.1016/S0140-6736(15)60515-3. . [Accessed November 2018].

13. Ghobarah H, Huth P, Russett B (2003). Civil wars kill and maim people-long after the shooting stops (2003). Centre for Basic Research in the Social Sciences. [Available online]. https://doi.org/10.1017/S0003055403000613 https://www.cambridge.org/core/journals/american-political-science-review/article/civil-wars-kill-and-maim-peoplelong-after-theshooting-stops/7E0EB818993415A57F08969803C8733B\# [Accessed January 2019].

14. Guha-Sapir, D., Rodriquez-Llanes, JM., Hicks, MH., Donneau, AF., Coutts, A., Lillywhite, L., Fouad, FM (2015). Civilian dealths from weapons used in the Syrian conflict. BMJ 2015;351-H4736. [Available online]. https://www.ncbi.nlm.nih.gov/pmc/articles/PMC5901879/. doi:1186/s13031-018-0150-4. [Accessed January 2019].

15. Hayani K, Dandashli A, Weisshaar E (2015). Cutaneous leishmaniasis in Syria: clinical features, current status and the effects of war. Acta Derm Venereol.2015;95:62-6. [Available Online]. https://www.medicaljournals.se/acta/content/abstract/10.2340/00015555-1988. [Accessed February 2019]. doi: 2340/00015555-1988.

16. ICD (2016). International Statistical Classification of Diseases and Related Health Problems 10th Revision. [Available Online]. https://icd.who.int/browse10/2016/en_.[Accessed February 2019].

17. Kim, G., Torbay, R., Lawry, L (2007). Basic health, women's health, and mental health among internally displaced persons in Nyala Province, South Darfur, Sudan. American Journal of Public health. 2007 Feb;97(2):353-61. [Available Online]. https://www.ncbi.nlm.nih.gov/pubmed/17138925. [Accessed February 2019].

18. Lancet, (1995). Humanitarian Olympics: Solferino to Goma. Lancet. Mar 4;345: (8949):529-30. 
19. Levy BS, Sidel VW, (1997). War and public health. (2 ${ }^{\text {nd }}$ Edition). New York: Oxford University Press; 1997.

20. Mateen, Carone, C., Al-Saedy, H., Nyce, S., Ghosn, J., Mutuerandu, T., Black, RE (2010) Medical conditions among Iraqi refugees in Jordan: data from the United Nations Refugee Assistance Information System (2012). [Available online]. https://www.ncbi.nlm.nih.gov/pmc/articles/PMC3370367 [Accessed December 2018].

21. Médecins Sans Frontières, (2019). The 5 things that we found after providing one million consultations in Cox's Bazar. [Available Online] https://www.msf.org/weve-provided-one-million-consultations-coxs-bazar-5-things-weve-found-bangladesh-rohingya_[Accessed February 2019].

22. MENTOR (2019). https://www.thementorinitiative.org/where-we-work/middle-east-region/syria/.

23. Merin, O., Nachman, A., Levy, G., Schwaber, M., Kreiss, Y (2010). The Israeli Field Hospital in Haiti - Ethical Dilemmas in Early Disaster Response. [Available online] https://www.nejm.org/doi/full/10.1056/NEJMp1001693 [Accessed December 2018].

24. Mollica, RF., Lopes Cardozo, B., Osofsky, HJ., Raphael, B., Ager, A., Salama, P(2004). Mental health in complex emergencies. [Available Online]. https://www.thelancet.com/article/S0140-6736(04)17519-3/fulltext.[Accessed May_2019].

25. Mowafi, H., Spiegel, P (2008). The Iraqi Refugee Crisis. Familiar problems and new challenges. [Available online] https://www.ncbi.nlm.nih.gov/pubmed/18398084 [Accessed December 2018].

26. Murray, C. J., King, G., Lopez, A. D., Tomijima, N., \& Krug, EG (2002). Armed conflict as a public health problem. BMJ (Clinical research ed.), 324(7333), 346-349. [Available Online] https://www.ncbi.nlm.nih.gov/pmc/articles/PMC1122272/. doi:10.1136/bmj.324.7333.346. [Accessed October 2018].

27. Ratnayake, R., Degomme, O., Bayard Roberts B., Spiegel, P (2014). Editorial: Conflict and Health: seven years of advancing science in humanitarian crises. Conflict and Health 2014: 8:7. [Available Online] https://doi.org/10.1186/1752-1505-8-7

28. https://conflictandhealth.biomedcentral.com/articles/10.1186/1752-1505-8-7 [Accessed November 2018].

29. REACH (2017). REACH Initiative (http://www.reach-initiative.org). [Available Online] http://www.reach-initiative.org/syria-reach-informson-sectoral-needs-of-the-over-22000-refugees-and-idps-populating-al-hol-camp [Accessed November 2018].

30. REACH (2017). Camp Profile Al Hol, North Eastern Syria (NES). Al Hasakeh Governante May 2017 [Available online]. http://www.reachresourcecentre.info/system/files/resource-documents/reach_syr_camp_profiling_al_hol_may_2017_final.pdf [Accessed November 2018].

31. REACH, 2018. Camp Profile Al Hol, North Eastern Syria (NES). Al Hasakeh Governante July 2018 [Available online] https://reliefweb.int/sites/reliefweb.int/files/resources/reach_syr_factsheet_camp_profiles_round_3_al_hol_refugees_august_2018_0.pdf [Accessed November 2018].

32. Rehman, K., Walochnik, J., Mischlinger, J., Alassil, B., Allan, R., Ramharter, M (2018). Leishmaniasis in Northern Syria during Civil War. Volume 24, Number 11-November 2018. [Available online]. https://wwwnc.cdc.gov/eid/article/24/11/17-2146_article. [Accessed December 2018].

33. Rehman, K., Walochnik, J., Mischlinger, J., Alassil, B., Allan, R., \& Ramharter, M. (2018). Leishmaniasis in Northern Syria during Civil War. Emerging Infectious Diseases, 24(11), 1973-1981. [Available online] https://dx.doi.org/10.3201/eid2411.172146. [Accessed December 2018].

34. Sahloul,MZ., Monla-Hassan, J.,Sankari, A., Kherallah, M., Atassi, B., Badr, S., Abbara, A., Sparrow, A (2015). War is the Enemy of Health. Pulmonary, Critical Care, and Sleep Medicine in War-Torn Syria. [Available online] https://www.ncbi.nlm.nih.gov/pubmed/26784922. https://doi.org/10.1513/AnnalsATS.201510-661PS. [Accessed November 2018].

35. Salam N, Al-Shaqha WM, Azzi A (2014). Leishmaniasis in the middle East: incidence and epidemiology. PLoS Negl Trop Dis. 2014 Oct 2;8(10). [Available Online]. https://www.ncbi.nlm.nih.gov/pmc/articles/PMC4183486/ [Accessed February 2019] doi: $1371 /$ journal.pntd.0003208.

36. Singh, S., Orbinski, J.J., Mills, E.J (2007). Conflict and health: a paradigm shift in global health and human rights. Conflict and Health 1:1. [Available online]. https://doi.org/10.1186/1752-1505-1-1_[Accessed November 2018]. 
37. SPHERE Project: Sphere Handbook. Volume 2011. [Available online] http://www.sphereproject.org/handbook [Accessed November 2018].

38. Spiegel, P., Checchi, F., Colombo, S., Paik, E (2010). Health-care needs of people affected by conflict: future trends and changing frameworks. Lancet Vol: 375, Issue 9711 P. 341-345. [Available online]. https://doi.org/10.1016/S0140-6736(09)61873-0 [Accessed November 2018].

39. Simmonds, S., Vaughan, P., S. William, Gunn, S (1983). Refugee Community Health. Oxford University Press.

40. UNHCR, (2007). United Nations High Commissioner for Refugees, UN Refugee Agency. Handbook for emergencies. Third edition 2007. [Available Online] https://www.refworld.org/docid/46a9e29a2.html [Accessed 31 December 2018].

41. UNHCR, (2014). Global Strategy for Public Health Public Health - HIV and Reproductive Health - Food Security and Nutrition Water, Sanitation and Hygiene (Wash) A UNHCR Strategy (2014-2018). [Available Online] https://www.unhcr.org/protection/health/530f12d26/global-strategy-public-health-unhcr-strategy-2014-2018-public-health-hiv.html [Accessed 31 December 2018].

42. UNHCR (2015). Health Data for Syrian refugees: Iraq, Jordan, Lebanon. Annual Report. 2013. [Available Online] https://data2.unhcr.org/en/documents/details/40686. Accessed 31 December 2018].

43. UNHCR, (2018). United Nations High Commissioner for Refugees. Statistical report on UNHCR registered Iraqis in Syria. Geneva: UNHCR;2018. [Available Online] https://data2.unhcr.org/en/documents/download/62515 [Accessed 31 December 2018].

44. UNHCR, (2018). United Nations High Commissioner for Refugees. Figures at a glance, Statistical Yearbooks. [Available Online]. UNHCR https://www.unhcr.org/figures-at-a-glance.html. [Accessed 31 December 2018].

45. van Berlaer G, Elsafti AM, Al Safadi M, Souhil Saeed S, Buyl R, Debacker M, (2017). Diagnoses, infections and injuries in Northern Syrian children during the civil war: A cross-sectional study. PLoS ONE 12(9): [Available Online] https://doi.org/10.1371/journal.pone.0182770 [Accessed 31 December 2018].

46. WHO, (2002). World Health Organization. Environmental health in emergencies and disasters: a practical guide. (Eds) B. Wisner, B., Adams, J. Geneva: World Health Organization. [Available Online] http://www.who.int/iris/handle/10665/42561 [Accessed 31 December 2018].

47. World Health Organization Health Statistics 2018. Monitoring Health for the SDGs. 2018. [Available Online] https://apps.who.int/iris/bitstream/handle/10665/272596/9789241565585-eng.pdf?ua=1_[Accessed May 2019].

48. World Health Organization Health Statistics 2018. The Impact of Chronic Disease in Iraq. [Available Online] https://www.who.int/chp/chronic_disease_report/media/impact/iraq.pdf?ua=1. [Accessed May 2019].

49. Yanni, EA., Naoum, N., Odeh, P., Han, M., Coleman, M., Burke, H (2013). The Health Profile and Chronic Diseases Comorbidities of USBound Iraqi Refugees Screened by the International Organization for Migration in Jordan: 2007-2009. [Available Online] https://link.springer.com/article/10.1007\%2Fs10903-012-9578-6_[Accessed May 2019].

\section{Figures}

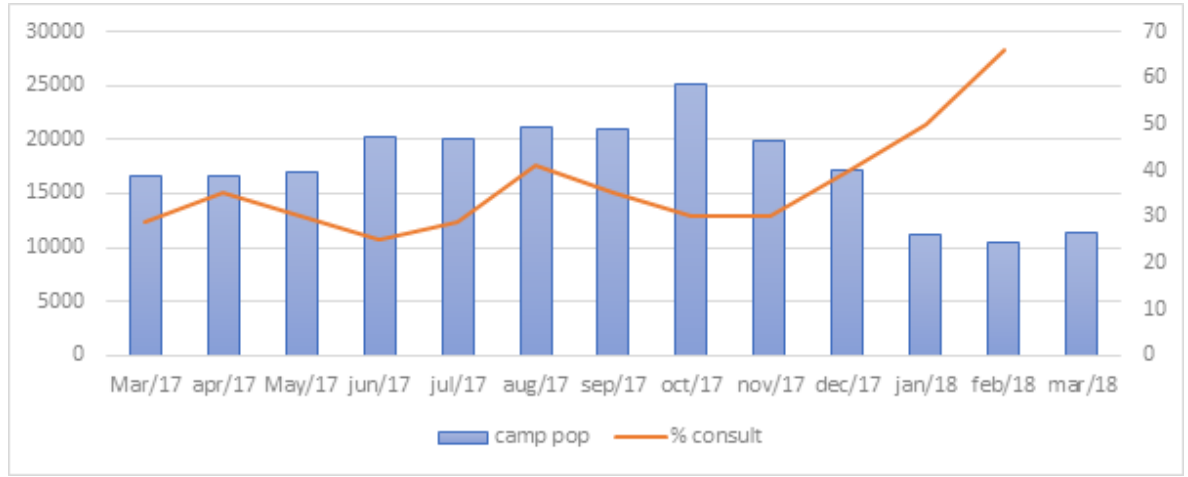

Page 14/17 


\section{Figure 1}

Percentage of Al-Hol camp population seeking health services per month

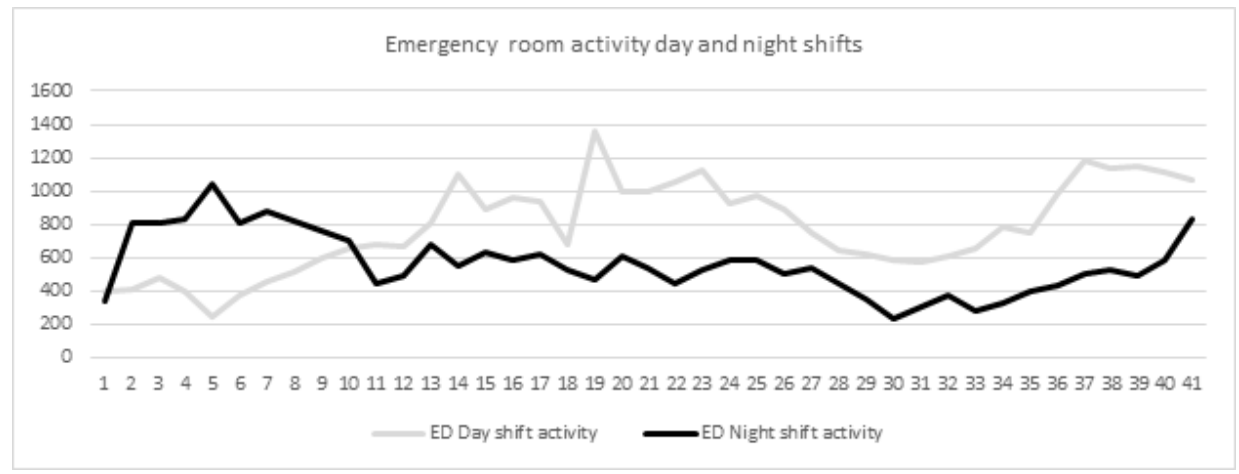

\section{Figure 2}

Emergency room activity ( $\mathrm{n}$ consultations) during day and night shifts over time

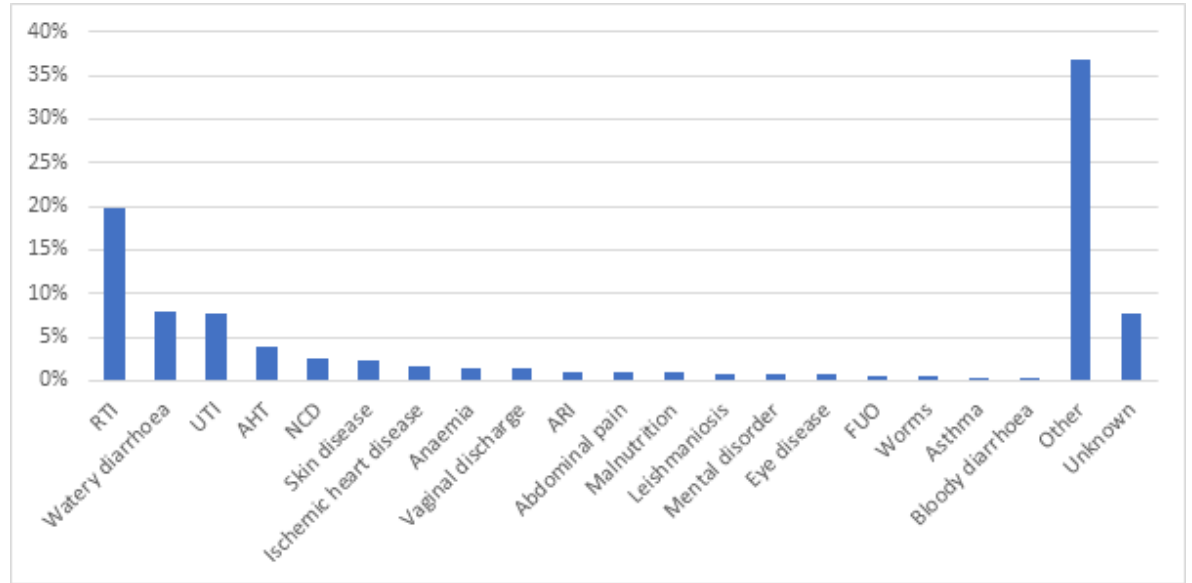

\section{Figure 3}

Individual diagnoses in \% of total diagnoses over the whole study period

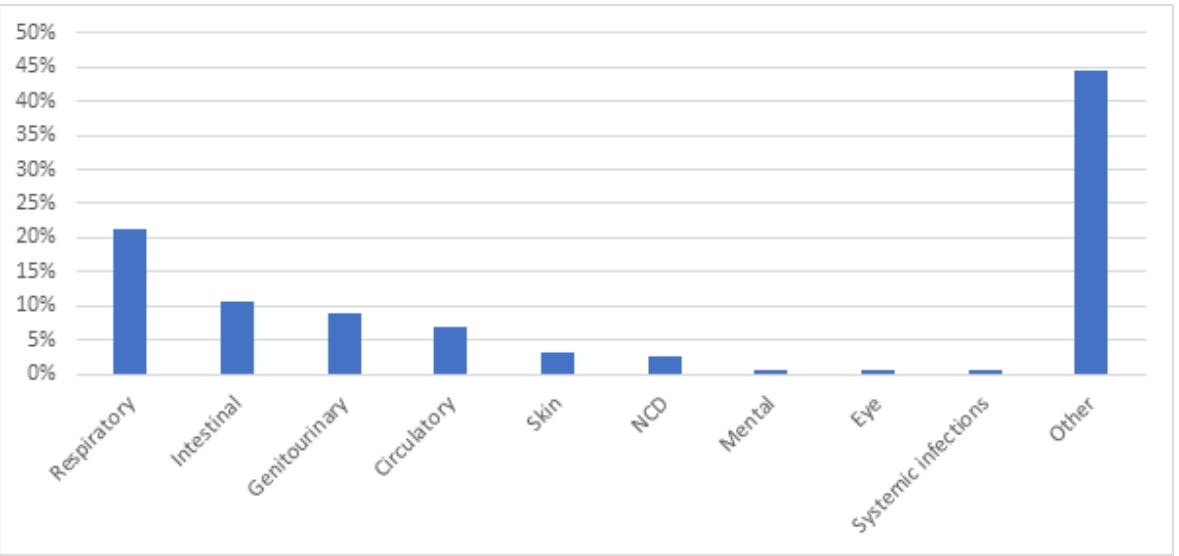

Figure 4

Categories of diagnoses in \% of total diagnoses over the whole study period 


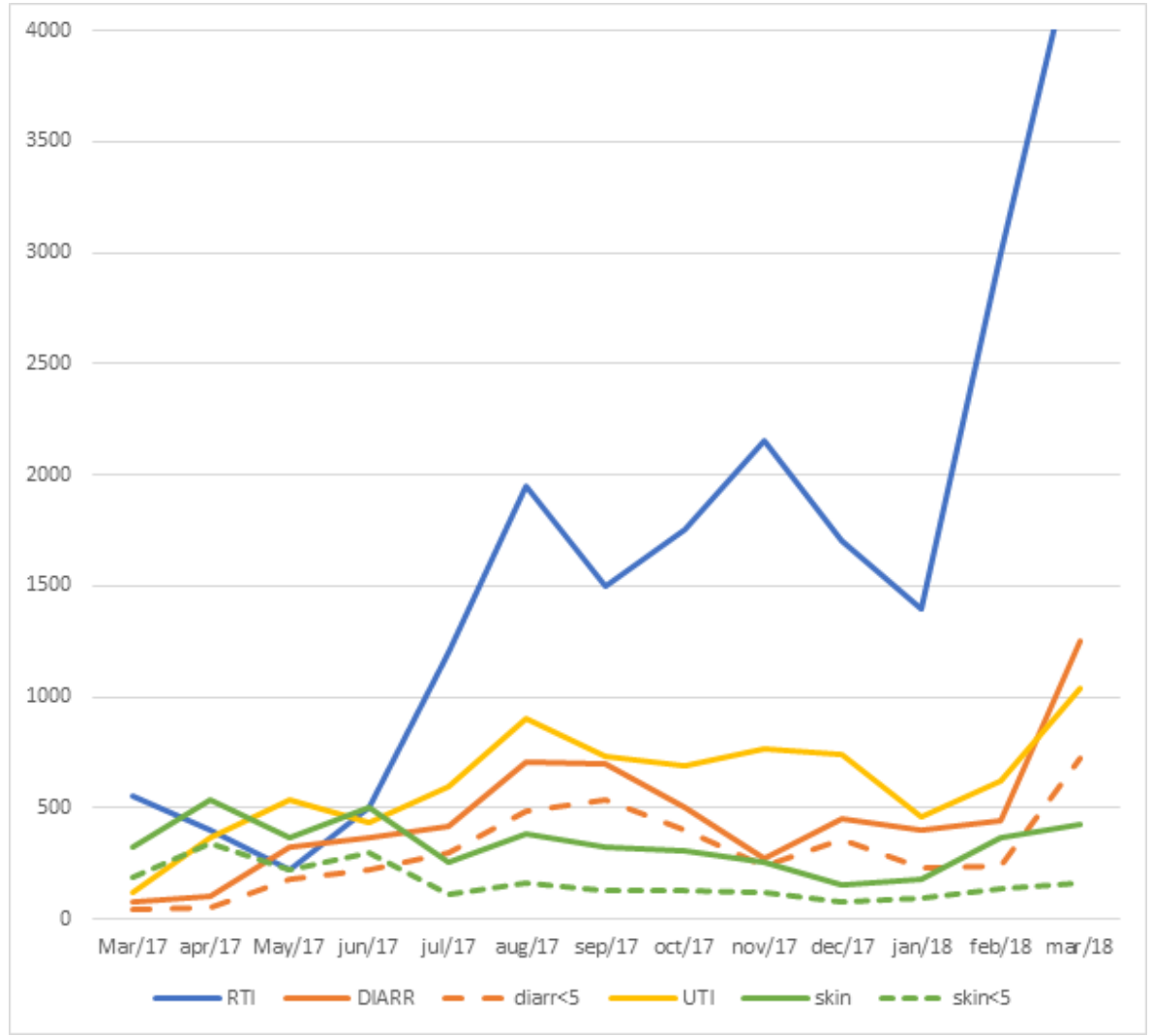

\section{Figure 5}

Progression of total numbers of patients $(\mathrm{n})$ with most frequent diagnosis categories over the study period

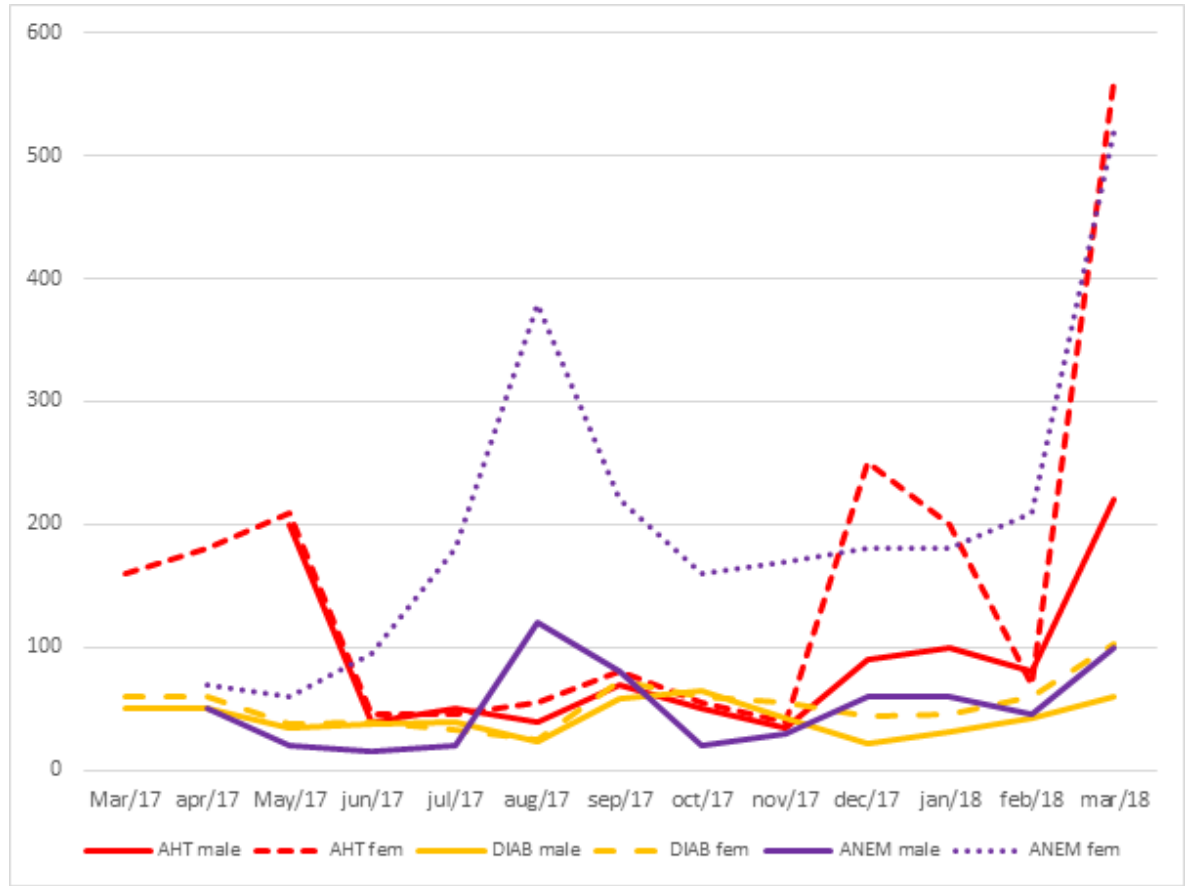

\section{Figure 6}

Progression of total numbers of patients ( $n$ ) with the most common noncommunicable diseases over the study period 


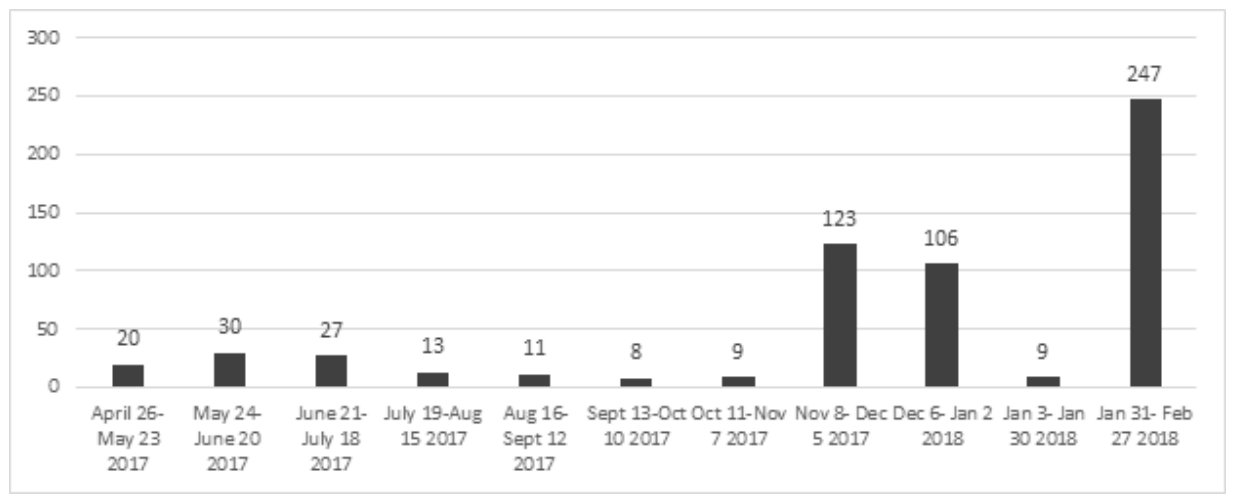

Figure 7

Number of patients $(\mathrm{n})$ presenting with mental health disorders over time.

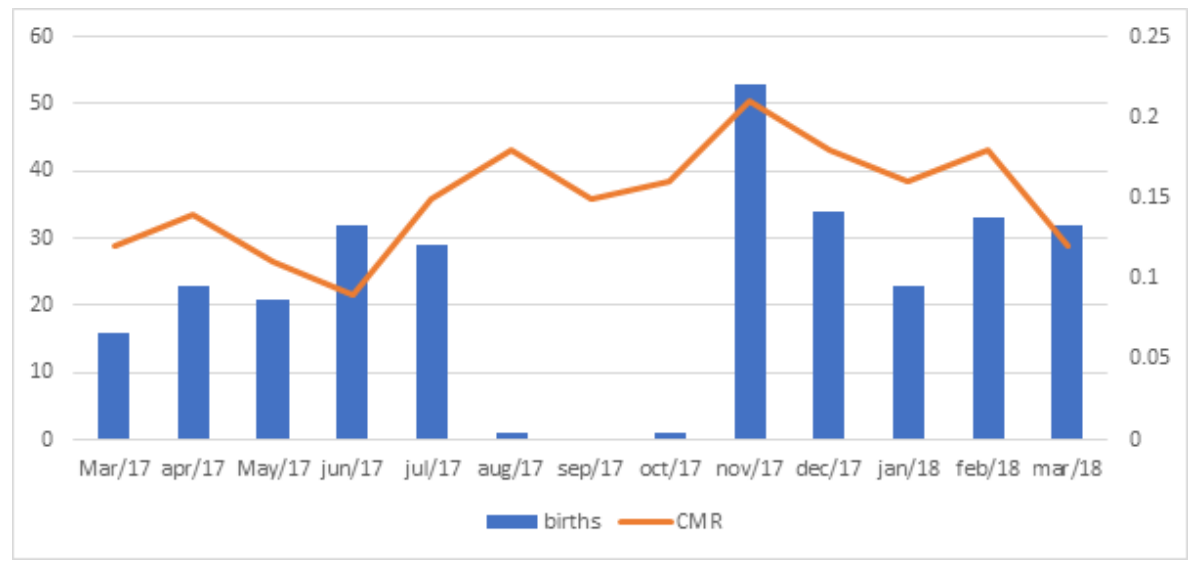

Figure 8

Number of live births (n) and crude mortality rates (fraction) per month.

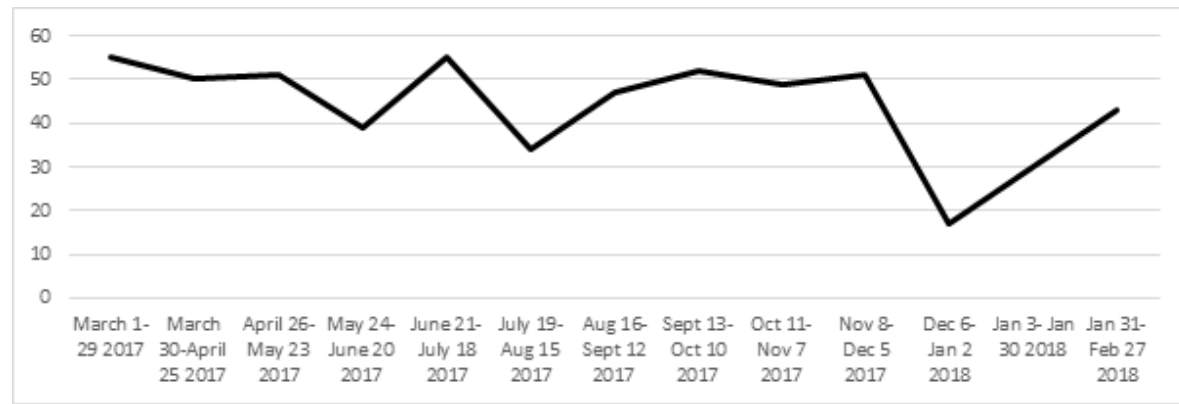

Figure 9

Monthly referrals (n) to specialist services or for emergency care outside the Al-Hol camp

\section{Supplementary Files}

This is a list of supplementary files associated with this preprint. Click to download.

- SUPPLEMENTARYONLINEMATERIAL.docx 